\title{
Dos desafíos de la teoría de los derechos: inmigración y pluralismo cultural*
}

\author{
RAFAEL DE ASÍS**
}

\begin{abstract}
SUMARIO: I. IGUALDAD Y DIFERENCIACIÓN EN EL DISCURSO DE LOS DERECHOS.- HUMANOS. II. INMIGRACIÓNY PLURALISMO CULTURAL.1. DERECHOS HUMANOS E INMIGRACIÓN.- 2. EL PAPEL DE LOS DERECHOS HUMANOS EN LA GESTIÓN DE LA DIVERSIDAD CULTURAL
\end{abstract}

A la teoría de los derechos humanos, entendida como aquella rama que se ocupa de cuestiones relativas al concepto y al fundamento de los derechos, a su teoría jurídica y a su historia, se le presenta una serie de desafíos. En este trabajo, analizaré dos: el tratamiento de la inmigración y la gestión de la diversidad cultural.

\section{IGUALDAD Y DIFERENCIACIÓN EN EL DISCURSO DE LOS DERECHOS HUMANOS}

Como es sabido, existen diferentes concepciones sobre los derechos humanos que, por otro lado, se manifiestan en el ámbito político y social. Así, los derechos humanos son utilizados para justificar invasiones e intervenciones en determinados Estados y, al mismo tiempo, las mismas invasiones e intervenciones son rechazadas al apelar a los derechos humanos. Igualmente, existen políticas públicas que se justifican desde los derechos humanos y, más concretamente, desde el principio de igualdad; sin embargo, esas mismas políticas son criticadas por algunos, quienes toman como referencia los derechos y el principio de igualdad.

Los derechos aparecen vinculados tradicionalmente a una serie de valores entre los que destacan el de la libertad y el de la igualdad. Sin embargo, su relación con el primero es menos cuestionado que con el segundo. Dicho de otra forma, si bien todas las posiciones sobre los derechos aceptan el papel de la libertad como referente esencial de estos instrumentos, no todas las teorías de los derechos pueden ser consideradas como igualitarias, al menos no en un sentido íntegro.

Y cuando digo esto me refiero a que no pueden ser consideradas igualitarias en un sentido íntegro ya que no incorporan las dos dimensiones esenciales de la igualdad, esto es, la de la diferenciación negativa y la de la diferenciación positiva. Ciertamente, la diferenciación negativa —es decir, la no diferenciación - está presente generalmente en las concepciones sobre los derechos, mientras que la diferenciación positiva no siempre es

* Este trabajo se ha realizado en el marco del Proyecto Consolider-Ingenio 2010, «El tiempo de los derechos». CSD2008-00007.

** Miembro del Instituto de Derechos Humanos Bartolomé de las Casas y del Departamento de Derecho Internacional, Eclesiástico y Filosofía del Derecho, de la Universidad Carlos III de Madrid. 
aceptada. Esto es consecuencia de la asunción de una idea de igualdad formal como punto de partida a la hora de concebir los derechos.

Pues bien, considero que una correcta teoría de los derechos debe cambiar este punto de partida y así iniciar el tratamiento de la igualdad desde la diferencia. En efecto, los seres humanos somos diferentes por nuestros rasgos físicos, por nuestras creencias, por nuestras capacidades, por nuestras habilidades... Así, los derechos se presentan como instrumentos que pretenden favorecer diferentes planes de vida, esto es, como instrumentos que favorecen el logro de una vida humana digna. Y en este ámbito, la igualdad aparece como un principio para la distribución de los derechos. La temática central de la igualdad equivale a establecer qué diferencias son relevantes para justificar un trato distinto y qué diferencias no lo son. La propia historia de los derechos puede ser descrita desde estos referentes.

No se puede hablar propiamente de derechos humanos hasta la modernidad ${ }^{1}$. En este contexto, la idea de los derechos se origina en el marco de tres grandes reflexiones: la de los límites al poder político, la de los límites al poder religioso y la de la humanización del Derecho penal y procesal. Estas tres reflexiones se manifestarán en forma de reconocimiento de derechos, y darán lugar a lo que se ha denominado «proceso de positivación», primer proceso de la historia de los derechos, que será seguido por el de «generalización», el de «internacionalización» y, finalmente, por el de «especificación»².

Así, el proceso de positivación expresa el paso de los derechos del mundo de las ideas al ámbito jurídico. En este sentido, supone la incorporación de los derechos a documentos jurídicos. Implica así la toma de conciencia de la necesidad de que aquellas carencias, exigencias, pretensiones y demás aspectos que atañen al desenvolvimiento moral del ser humano sean incorporadas al Derecho positivo.

Durante este proceso está presente una idea de igualdad formal pero muy distante de la universalidad. Lo que quiero decir con ello es que en este momento se considera que los derechos pertenecen a todos seres humanos, pero no todas las personas forman parte de esta categoría.

Así, las concepciones que apoyan el proceso de positivación, defensoras de la igualdad formal pero no de la universalidad, serán sustituidas en la historia por planteamientos que, por diferentes caminos, tratarán de extender a todas las personas la idea del ser humano como ser valioso en sí mismo. Y precisamente esta será la idea latente en el proceso de generalización.

Así, el proceso de generalización supone la ampliación de la titularidad de los derechos a otros sectores de la población. Es un intento por dar

1 Véase Peces-Barba, Gregorio y Eusebio Fernández. Historia de los derechos fundamentales. Tomo I. Tránsito a la modernidad. Siglos XVI y XVII. Madrid: Universidad Carlos III-Dykinson, 1998. También PecEs-BarBA, Gregorio et al. Historia de los derechos fundamentales. Tomo II. Siglo XVIII. Madrid: Universidad Carlos IIIDykinson, 2001.

2 Véase Peces-Barba, Gregorio et al. Lecciones de derechos fundamentales. Madrid: Dykinson, 2006. 
coherencia al discurso de los derechos y a la realidad: un discurso de derechos que se entienden como naturales, esto es, como pertenecientes a todos los seres humanos; y una realidad que circunscribía su disfrute a una clase social determinada, representada por la burguesa. Un discurso basado en la defensa de la igualdad natural de los seres humanos; una realidad susceptible de ser descrita en términos de desigualdad.

En este sentido, en el proceso de generalización se maneja una idea de igualdad como no diferenciación, una idea de igualdad formal compatible ahora sí con la defensa de la universalidad. Y esta defensa de la universalidad trae consigo, en un segundo momento de la generalización, de manera paradójica, la introducción de la diferenciación positiva. En efecto, el proceso de generalización tiene dos grandes momentos. El primero de ellos corresponde a la visión que hemos presentado en su primera aproximación. El segundo se caracteriza por la introducción de la idea de igualdad como diferenciación positiva, como mecanismo para conseguir una igual satisfacción de los derechos, aunque ello suponga renunciar a la universalidad jurídica.

Junto a los dos procesos que hemos presentado, es posible referirse también al de internacionalización, que expresa el reconocimiento de los derechos en el plano internacional y, con ello, el establecimiento de sistemas de garantías de carácter supraestatal. Los primeros signos de este proceso se encuentran en la lucha por la abolición de la esclavitud, en el impulso al Derecho humanitario y en la protección a las minorías. En este proceso aparecen las dos dimensiones de la igualdad que estamos señalando dentro del discurso de los derechos.

Por último, es posible hablar de un cuarto proceso, denominado «de especificación», que se caracteriza por la aparición de textos jurídicos en los que se reconocen derechos específicos de ciertos colectivos. En este sentido, el proceso de especificación utiliza una idea de igualdad como diferenciación positiva, al igual que lo hacía el proceso de generalización en su segundo momento. Sin embargo, a diferencia del proceso de generalización, la justificación del reconocimiento de derechos específicos se hace no desde el punto de vista del logro de una satisfacción general de los derechos, sino apelando al valor de la diversidad, desde la exaltación del valor que poseen los colectivos afectados. Lo que caracteriza a este proceso es la nota de la especificidad o, si se prefiere, de la diversidad predicada sobre un sujeto o un grupo. El proceso de especificación tiene que ver con el reconocimiento de derechos derivados de rasgos que identifican a un sujeto o a un colectivo - por ejemplo, los derechos de los pueblos indígenas-. De esta forma, el proceso de especificación matiza el ideal de universalidad propio de los derechos.

En este sentido, la igualdad y la diferencia son dos constantes de la teoría de los derechos que deben tomarse en cuenta al abordar su proyección sobre cualquier fenómeno. 


\section{INMIGRACIÓN Y PLURALISMO CULTURAL}

El título de este apartado permite plantearse dos preguntas distintas: ¿cómo gestionar los procesos migratorios desde los derechos? y, icómo abordar la cuestión cultural desde los derechos? Obviamente, las preguntas pueden relacionarse en la medida en que se analice el fenómeno migratorio y se atienda a la cuestión cultural. Se trata, en todo caso, de dos de los grandes desafíos contemporáneos de los derechos.

\section{Derechos humanos e inmigración}

Como es sabido, las políticas en materia de inmigración se asientan sobre tres pilares básicos: las relaciones entre los Estados, la cuestión de la recepción y la de la integración. El primero de los pilares no afecta solo a los países que reciben población migrante y a los países de donde procede dicha población, sino al conjunto del sistema político internacional. Lo que se quiere decir con ello es que la cuestión de la inmigración exige estrategias políticas de carácter internacional. El segundo de los pilares, el de la recepción, tiene como cuestión central la de la existencia o inexistencia de límites a la migración. Por último, el tercer pilar nos sitúa frente al tema de la existencia o no de razones que permitan diferenciar el disfrute de los derechos en relación con los inmigrantes. Es evidente que en el tratamiento de los tres pilares las cuestiones de la igualdad y la diferencia están presentes. Por lo demás, las reflexiones sobre el papel de los Estados son válidas para las asociaciones, agrupaciones y uniones de Estados.

Pues bien, el tratamiento del primer pilar, el de las relaciones entre los Estados, suele realizarse sobre la base de diferentes argumentos, entre los que destacaré cuatro: la existencia de lazos históricos entre los Estados, la existencia de lazos culturales, la prosperidad o la pobreza de los Estados, y la reciprocidad entre los Estados. El primer y tercer argumento será abordado desde el segundo de los pilares, esto es, el de la recepción. Por su parte, el segundo afecta a la cuestión de la diversidad cultural, por lo que será tratado al referirme a dicho tema. Por último, el argumento de la reciprocidad, aunque es habitualmente utilizado en el ámbito de la discusión sobre los derechos, tiene un difícil acomodo en la teoría de los derechos, al menos si nos tomamos en serio el postulado de que estos quedan fuera del regateo y del negocio.

El punto de partida del tratamiento de lo que he denominado «cuestión de la recepción» suele ser la interpretación consolidada del artículo 13,1 de la Declaración Universal de Derechos Humanos. Dicho artículo establece: «Toda persona tiene derecho a circular libremente y a elegir su residencia en el territorio de un Estado». Lo que he denominado «interpretación consolidada» consiste en afirmar que este precepto reconoce el derecho a salir de un país, pero que no reconoce el derecho a entrar en un país ni a permanecer dentro de él.

Esta interpretación consolidada provoca que, cuando abordamos la cuestión de la recepción, se parta ya desde el principio de la inexistencia 
de este derecho, con lo que el discurso está así condicionado en su origen. Entonces, lo habitual es encontrarnos con planteamientos que señalan cuándo está justificado sobrepasar esa restricción. Sin embargo, creo necesario modificar el punto de partida, en el sentido de iniciar la reflexión considerando que existe un derecho de entrada que, como todos los derechos, puede verse limitado ante una serie de circunstancias relevantes.

De esta forma, la cuestión de la recepción debe ocuparse de examinar cuándo está justificado establecer límites al derecho de entrada en un territorio. Existen criterios que claramente no pueden ser tomados en cuenta y criterios que pueden generar dudas. Junto a ellos, existen criterios que se presentan como poderosamente justificados a la hora de facilitar libertad de movimiento y posibilidad de entrada en un determinado Estado.

Comenzaré por estos últimos. Es posible referirse a situaciones en las que la admisión de inmigrantes es una obligación moral, en el marco de una teoría de los derechos. Desde el examen de esas situaciones, es posible aludir a una serie de criterios que tienen en cuenta las relaciones familiares, las persecuciones por motivos políticos o la existencia de peligro para la vida o la integridad física de las personas — criterios que se relacionan, por tanto, con situaciones de insatisfacción de necesidades básicas-.

Entre los criterios que no pueden ser considerados al restringir la recepción de inmigrantes, se cuentan los relativos a la raza, la religión, la etnicidad o la orientación sexual. Se trata de criterios que están normalmente expuestos en el ámbito de las normas sobre no discriminación. La justificación de medidas discriminatorias apoyadas en este tipo de criterios no tiene cabida en el marco de una teoría de los derechos, como tampoco la tiene criterios que tengan que ver con la nacionalidad o con la utilización del principio de reciprocidad.

Los criterios que considero que pueden plantear dudas son al menos los siguientes: los referidos al potencial económico, a los lazos históricos, a la condición de delincuente del sujeto, o al padecimiento de algún tipo de enfermedad. Es importante advertir que, cuando me refiero a la posible justificación de estos criterios, lo hago desde el presupuesto de que no existieran otros argumentos del tipo de los que antes presenté como favorecedores de la recepción. Quiero decir con ello que la posible justificación de estos criterios solo es operativa cuando no se está ante alguna de las circunstancias que apoyan la recepción de los sujetos. A partir de ahí, el peso de estos criterios dudosos, en una temática como la que nos ocupa, dependerá de la situación concreta en la que nos encontremos.

En todo caso, y en relación con los cuatro casos dudosos, creo que los relativos al potencial económico, a la condición de delincuente del sujeto o al padecimiento de alguna enfermedad poseen un significado diferente 
al de los lazos históricos. En efecto, este último presenta dificultades en su utilización como criterio diferenciador de los derechos. Y ello, en primer lugar, porque exige operar con el criterio de la nacionalidad, que tiene un acomodo difícil en el ámbito de la teoría de los derechos. $\mathrm{Y}$, en segundo lugar, porque responsabiliza a sujetos e instituciones del presente con actuaciones de generaciones pasadas. A pesar de ello, en el ámbito de las relaciones bilaterales, puede ser un criterio de segundo orden, esto es, operativo una vez que se han satisfecho otros.

El criterio del potencial económico se refiere a la posibilidad de establecer límites para el ingreso en un determinado Estado considerando la situación económica en la que este se encuentre y el perfil del sujeto que demanda el ingreso. Es también un criterio de compleja recepción por parte de la teoría de los derechos. Exige un análisis serio y riguroso de la situación y de los valores y los derechos implicados. Ahora bien, conviene no perder de vista cómo la idea de solidaridad posee sus límites y que el rechazo total a este criterio puede enfrentarse a algunos de dichos límites.

La condición de delincuente del sujeto es un criterio que, de nuevo, está conectado con la cuestión de los límites a la solidaridad. Ahora bien, su operatividad exige tener en cuenta el tipo de delito que puede servir de razón para la limitación de la entrada. Así, con carácter general, este criterio adquiere consistencia cuando estamos hablando de delitos contra los derechos humanos. En el resto de los casos, su justificación deja de tener sentido en el marco de la teoría de los derechos.

Por último, el criterio relativo al padecimiento de alguna enfermedad solo puede adquirir fuerza en el marco de un sistema de salud pública presidido por los derechos. Asimismo, se trata de un criterio que está irremediablemente conectado con alguno de los criterios que expuse para el favorecimiento de la recepción. En efecto, hemos hecho referencia a situaciones de peligro para la vida y la integridad física de las personas. En este sentido, y en coherencia con ese discurso, podríamos pensar en la posibilidad de justificar medidas de admisión, o de rechazo, si tenemos en cuenta la situación médica en la que se encuentra el inmigrante.

Es importante advertir cómo la justificación o no de estos criterios está condicionada por la situación concreta del país receptor. Pero, además, estos criterios deben ser enmarcados dentro de una reflexión centrada en los derechos con proyección internacional y en los que la solidaridad desempeñe un papel esencial. Lo que quiero decir con ello es que resulta sumamente difícil en este punto establecer reglas generales que valgan para todo país y que, además y como consecuencia de lo anterior, dado que se trata de un asunto que compete también - y en una medida importante- a los habitantes del país ${ }^{3}$, debe ser 
abordada desde los referentes de un discurso solidario o igualitario de índole nacional e internacional.

Pues bien, si no parece posible justificar que el Estado no pueda en momento alguno establecer límites a la entrada en su territorio, y que por lo tanto es posible hablar de límites a ese supuesto derecho a inmigrar, tampoco me parece, y en este caso porque me resulta contradictorio con una teoría correcta de los derechos, que sean únicamente los propios Estados los que cuenten a la hora de adoptar esa decisión. Un papel importante en esta cuestión debe ser desempeñado por el sistema jurídico internacional: eso sí, siempre y cuando esté presidido por los derechos. Y en todo caso, y dado que la atención a la opinión de los habitantes del país es también esencial en este punto, es importante concienciar a estos del significado de los derechos. En todo ello, la solidaridad como expresión de esa concienciación y como justificación de políticas normativas adquiere una relevancia fundamental, y tiene que proyectarse no solo en la situación del sujeto con el que se plantea el ser solidario sino también con la de la sociedad a la que se exige ser solidaria.

Una vez planteada la cuestión de la recepción, surge la de cómo tratar al inmigrante o, dicho de otra manera, cómo plantear la cuestión de la integración. En este ámbito entran en juego dos planos: el de la equiparación de los derechos y el del reconocimiento de derechos específicos. Y ciertamente la cuestión dista mucho de ser resuelta de modo indubitado. Así, conviene advertir de que, aunque algunos criticamos la idea de nacionalidad como fuente de derechos y su inclusión en este discurso, otros la ensalzan como vínculo garante de diversidad e identidad cultural ${ }^{4}$.

En todo caso, tradicionalmente se alude a dos grandes modelos de políticas en lo referente al tratamiento del inmigrante, que pueden ser identificadas con los términos de exclusión e inclusión ${ }^{5}$. Los primero son incompatibles con la teoría de los derechos, cosa que no ocurre con los segundos.

Ahora bien, existen diferentes modelos de inclusión. En efecto, estos modelos pueden ser, en términos culturales, monoculturales o pluriculturales; y más allá de estos términos, absolutistas o pluralistas. El ejemplo

seacogea los que están mal perosobre todoa los cercanos o parientes. Tal vez por eso seríamejor relacionar la comunidad con los clubes. Estos tienes su comité de admisión y sus objetivos diseñados. Por otrolado, no los relaciona con la vecindad, pues, según él, esta no establece límites de recepción. Justifica asíel poder de los Estados decontrolar los flujos como quieran. Ahora, una vezadmitidoel extranjero, debe ser equiparado. Véase al respecto WALzer, M. Las esferas de la justicia. México: Fondo de Cultura Económica, 1993, pp. 44 y siguientes. EnsentidoparecidoseexpresaA.Heller,quienparadefenderestaconcepcióndefiendeelsiguiente argumento:sialguiendeseaabandonarnuestracasapuedehacerlo;sialguiendeseaquedarseennuestracasa, somos los habitantes de la casa los que tenemos que decidirlo. HELLER, A. «Diez tesis sobre la inmigración». Diario El País, 30 de mayo de 1992, p. 14.

4 Así, por ejemplo, paraalgunos la sustitución de la ley nacional por la ley de la residencia habitual,enelámbito de la participación política, es reflejo de una política de asimilación.

5 JIMÉNEZ, C. «Modelos sociopolíticos e ideológicos ante la diversidad cultural: la propuesta intercultural». En J. Alcina Franch y Marisa Calés (editores). Hacia una ideología para el siglo XXI. Ante la crisis civilizatoria de nuestro tiempo. Madrid: Akal, 2000, pp. 132 y siguientes. Véase también una clasificación parecida en CosTALAscoux, J. De l'immigré au citoyen. París: La Documentation Française, 1989, pp. 10 y siguientes.

DOS DESAFÍOS

DE LA TEORÍA DE LOS DERECHOS: INMIGRACIÓN Y PLURALISMO CULTURAL 
fundamental del modelo monocultural o absolutista es el de las políticas asimilacionistas, que suponen la imposición de valores de la mayoría a grupos minoritarios. El modelo de asimilación, en términos culturales, conduce al predominio de una determinada concepción cultural. Supone el intento de homogeneizar la sociedad, al utilizar una idea de igualdad como exigencia de generalidad, que puede ser objeto de las mismas críticas que se suelen proyectar sobre esta idea — por ejemplo, la inexistencia de una situación real de igualdad—.

Por su parte, el modelo pluricultural o pluralista sostiene la posibilidad de convivencia entre grupos étnicos desde el respeto e incluso desde la promoción de la diferencia. Básicamente, estas políticas son las que suelen identificarse con el término integración en sentido estricto. Con ellas se pretende mantener la identidad cultural, pero compartida con la de la sociedad de acogida. Supone así el respeto a las concepciones morales de los individuos. Y en este punto se hacen ulteriores especificaciones.

A la hora de conectar estos diferentes modelos con los derechos humanos, no cabe duda de que el modelo de asimilación encuentra un problemático acomodo, siempre y cuando se trate de un modelo cerrado. Y digo esto porque para muchos el tratamiento de estas cuestiones desde los derechos es contemplado como expresión de una política asimilacionista. En este sentido, lo relevante es el tipo de asimilación, esto es, la teoría que se pretende imponer o desde la que se quiere asimilar. Y en esta línea es cierto que existen teorías de los derechos que pueden desempeñar esa función; es decir, es imposible negar que existan formas de entender los derechos humanos que se traducen en la elaboración de políticas asimilacionistas o de hegemonía cultural. No obstante, se trata de formas erróneas de entender los derechos: teorías que parten de la desconsideración del otro y que se alejan de la posición que aquí estamos manejando. De ahí que sea mejor plantear la referencia a los derechos desde los modelos pluralistas.

El reconocimiento jurídico de los derechos de los no nacionales suele moverse en torno a tres ejes fundamentales. En efecto, es habitual en esta materia considerar que existen derechos que poseen los no nacionales independientemente de cualquier circunstancia; derechos que poseen los no nacionales si así lo establece un tratado o una ley; y, por último, derechos que no poseen los no nacionales — salvo contadas excepciones que nos obligarían a diferenciar tipos de no nacionales, un ejercicio que no llevaré a cabo-.

Normalmente, cuando se hace referencia a la primera categoría de derechos, se habla de «derechos propios de la dignidad humana» para referirse a los derechos individuales y a algunos derechos sociales. Por su parte, en la tercera categoría se incluyen los derechos que tienen que ver con la idea de soberanía, la defensa o la función pública, y también, en ciertos casos, con la actividad asistencial del Estado. En 
este sentido, esta categoría hace referencia a los derechos políticos y a algunos sociales. La segunda categoría, entonces, tendrá que referirse a aquellos derechos, ya sean individuales o sociales, que no se muevan dentro de las coordenadas anteriores.

Así, de esta clasificación de deduce que existen derechos que corresponden tanto a nacionales como a no nacionales porque se entienden vinculados a la dignidad humana. Ciertamente, no creo que pueda sostenerse la existencia de derechos que no tengan que ver con la dignidad humana. En este sentido, podemos preguntarnos qué se quiere decir cuando se establece esta diferenciación y qué está detrás de ella. Pues bien, en este punto aparece un criterio de naturaleza política. Se trata precisamente de la nacionalidad, que se presenta como elemento relevante para condicionar el reconocimiento de los derechos.

Y un problema similar se nos presenta cuando volcamos nuestra reflexión hacia los derechos políticos. Este tipo de derechos, entre otras cosas, permiten que todos los sujetos de derechos participen en las tareas de atribuirles significado y distribuirlos. En este sentido, conceden legitimidad a las decisiones sobre los derechos. Pues bien, cuando se traslada esta problemática al ámbito de los no nacionales, otra vez vuelven a aparecer la nacionalidad y el Estado como determinantes del disfrute de los derechos.

El tratamiento de la cuestión de la integración se desarrolla así desde lo que podríamos denominar «paradigma de la nacionalidad», en el sentido de que la construcción de la idea de los derechos aparece siempre condicionada a la nacionalidad ${ }^{6}$. Y eso que he llamado «paradigma de la nacionalidad», presente en la construcción de los derechos, puede llegar a tornar incoherente la teoría de los derechos.

La presencia de la idea de la nacionalidad y su proyección en los derechos incide directamente y desmiente uno de los rasgos que tradicionalmente se utilizan para describirlos: la consideración de los derechos como límites al poder. La idea de nacionalidad, salvo que se le quiera dar una dimensión cultural —aspecto este que considero problemático y que en resumidas cuentas otorga a la idea de cultura el mismo papel que a la del poder-, solo tiene sentido y justificación desde la propia idea de poder, e implica en definitiva situar a este por encima de los derechos.

Igualmente, desmiente la exigencia de una justificación ética para todos aquellos casos que impliquen una diferenciación en el ámbito jurídico. La nacionalidad no es una razón moral que justifique la diferenciación, ni negativa ni positiva.

Sin embargo, como estamos viendo, en materia de derechos de los no nacionales, se produce una diferente atribución de los derechos que tiene como argumentos principales, por un lado, el de la nacionalidad

DOS DESAFÍOS

DE LA TEORÍA DE LOS DERECHOS: INMIGRACIÓN Y PLURALISMO CULTURAL 
y, por otro, los intereses del Estado. Un discurso coherente de los derechos implica considerar que toda diferenciación o que todo criterio de distribución de ellos debe poseer naturaleza moral. Ahora bien, la consideración de que la nacionalidad o los intereses del Estado son argumentos con peso moral puede ser problemática y objeto, en su caso, de matizaciones.

El argumento de la «identidad nacional», permite considerar que la pertenencia a una determinada nación, en sus diferentes dimensiones, es un criterio válido para asignar derechos. Pues bien, considero que se trata de un argumento enfrentado a una teoría de los derechos, y carente de justificación moral, si se utiliza como elemento de discriminación negativa, esto es, si se utiliza como criterio para dejar de reconocer derechos. El no reconocimiento de los derechos no puede estar basado en circunstancias como el nacimiento, la raza, la cultura, sino en todo caso en el cariz de las pretensiones que se demandan. Podría hablarse de la nacionalidad como un argumento que poseería un peso ético indirecto, a través de su relación con la idea del compromiso en la organización o también a través del rechazo al «hombre aprovechado». Sin embargo, se trata de argumentos problemáticos, ya que el compromiso en la organización como condición del disfrute de los derechos parece situar al Estado por encima de estos; porque no hay una conexión lógica entre «nacional» $\mathrm{y}$ «comprometido con la organización» ni entre «nacional»y «hombre no aprovechado»; y porque difícilmente puede pensarse que ese compromiso se produzca en relación con aquellos que no pueden participar en la propia organización.

Muchos de los intentos de justificar esa distinción entre nacionales y no nacionales presentando razones de peso moral coinciden en un punto: la contribución al gasto público. Parece que es esta exigencia la que está detrás de la distinción y la que justificaría - fuera de los razonamientos que aluden al orden público o a la seguridad, que por otro lado pueden peligrar también por la acción de los nacionales- el trato desigual. Sin embargo, su adopción tiene consecuencias un tanto sorprendentes.

No es posible, con carácter general, pensar en la nacionalidad como una característica que justifique la diferenciación jurídica. No es una razón, y este es un discurso de razones. La distinción entre «nacional» $\mathrm{y}$ «extranjero» no encuentra justificación alguna desde una teoría ética que se mueva sobre la idea de la generalización.

Por otro lado, esa distinción también matiza la idea de la indivisibilidad de los derechos y la importancia que, al menos en la teoría, posee la autonomía pública de los individuos. En efecto, la diferenciación nacional-extranjero justifica el no reconocimiento de los derechos de participación política para estos últimos. Y ello se hace de nuevo desde la nacionalidad con los problemas que esta tiene y que acaban de ser apuntados en lo referente a su justificación. 
Todo ello implica no tomarse en serio la idea de dignidad humana y la universalidad, ante lo que se origina un círculo teórico del que es difícil salir. Este círculo teórico puede ser expuesto de manera simple como sigue: (a) el no reconocimiento de los derechos a unos sujetos que viven en el territorio del Estado se apoya en su carácter diferente; (b) este no reconocimiento implica que para estos sujetos el sistema jurídico político no sea legítimo; (c) la ausencia de legitimidad trae consigo que no puedan aducirse razones generales para obedecer el sistema jurídico político; (d) esa inexistencia de razones complica enormemente la integración de estos sujetos y perpetúa la argumentación sobre su carácter diferente.

La defensa de la equiparación en los derechos trae consigo dos problemas que no quiero pasar por alto. El primero se refiere a lo que puede suponer de homogeneización o de imposición de un modelo cultural; el segundo, muy unido al anterior, alude a la necesidad de que los sujetos equiparados acepten dicho modelo $-\mathrm{y}$, por tanto, los principios y las reglas que de él se deducen-. Pues bien, he señalado ya desde el principio mi opción en favor de una manera de entender los derechos - si se quiere, de la cultura de los derechos- y no me plantea problema alguno defender una homogeneización en ese sentido, sobre todo si se toma en cuenta que su referente es la igual dignidad humana. En este sentido, y en coherencia con lo anterior, los sujetos, independientemente de su nacionalidad o de cualquier otra dimensión, deberán adecuar sus comportamientos a dichos parámetros, y será esta una condición insuperable para que se produzca dicha equiparación y un paso previo para el examen de la diferenciación.

A pesar de que la diferenciación en la distribución de los derechos pueda ser presentada como contraria a la conexión derechos-sujeto moral, también es posible mantener esa conexión aludiendo a la satisfacción real de los bienes que están en juego. Ahora bien, en lo que al tema de los derechos de los no nacionales se refiere, no cabe defender que la nacionalidad sea un argumento válido que justifique esa diferenciación, salvo que con ella se pretenda precisamente satisfacer derechos a determinados colectivos. La cuestión en este punto radica en que si esa diferenciación se produce por el hecho de ser «nacional» de algún sitio o por el hecho de ser sujeto moral y encontrarse en una determinada situación. En este punto, creo que lo segundo debe prevalecer.

De cualquier modo, la teoría de los derechos no puede asumir planteamientos que choquen con sus referentes esenciales, ya sean planteados desde un punto de vista individual o ya sean justificados en un supuesto interés nacional o cultural. Evidentemente, la teoría de los derechos se constituye así en un modelo que, a pesar de ser enormemente abierto, puede cerrase a otros modelos. Y digo que es «enormemente abierto» porque el cierre de este modelo - tal vez cultural — solo se produce en relación con ciertas exigencias básicas (independencia y autonomía moral, satisfacción de necesidades básicas y participación). 
Por otro lado, y desde una óptica realista, conviene no pasar por alto cómo la cuestión de la equiparación dista mucho de estar resuelta. En este sentido creo que el reto prioritario en el ámbito de la inmigración sigue siendo el del reconocimiento generalizado de los derechos; así, no se trata tanto de discutir en primer lugar sobre aquello que nos diferencia sino más bien sobre aquello que nos une: la dignidad humana. Además, el reconocimiento de la igual participación permitirá el diálogo y el cuestionamiento, en su caso, de los principios y las reglas que se deducen de la teoría de los derechos.

Desde las reflexiones efectuadas, considero que, para hacerla más compatible con la teoría de los derechos, la política de integración debe tener como punto de partida los siguientes referentes:

a) la consideración de que existe un derecho a inmigrar, obviamente limitado - como todos lo derechos-, si bien en caso alguno por motivos de raza, religión o etnia;

b) la desaparición del criterio de la nacionalidad como argumento genérico válido para la diferenciación negativa de los derechos;

c) el establecimiento de una política abierta en el mayor grado posible a la participación política y cultural de los no nacionales; y,

d) la configuración de una política solidaria centrada en los derechos y, a través de ellos, en el respeto a la diferencia, que tenga como proyección principal el diseño de una educación coherente con ello.

Como he venido señalando, la utilización del criterio de la nacionalidad para el establecimiento de diferenciaciones entre los derechos se enfrenta a un correcto entendimiento de su sentido y significado. La nacionalidad no es un argumento moral. Ahora bien, dicho criterio puede jugar un determinado papel en este ámbito, de manera indirecta, a través del principio del orden público. En este caso, la nacionalidad no opera como argumento moral sino como argumento técnico racional de ordenación del ejercicio y disfrute de los derechos, que se tiene en consideración a la vista de la tradicional configuración de los Estados.

Para explicar lo anterior, me referiré de forma breve a la cuestión de la participación política de los inmigrantes. Como es sabido, en la actualidad suele argumentarse sobre la necesidad de sustituir el paradigma de la nacionalidad por el de la residencia, para con ello integrar en el ámbito de la participación política a los inmigrantes. No obstante, no hay que pasar por alto que este discurso - que yo mismo defiendo- sigue utilizando la nacionalidad, por ejemplo, en lo referente a los inmigrantes no residentes o en lo referente a los nacionales no residentes. Sin embargo, la justificación de estas dos excepciones es diferente. En el segundo caso, la nacionalidad parece presentarse como un argumento moral — de difícil cabida según lo afirmado en este trabajo, salvo que entendiéramos que la limitación de ese criterio solo afecta a la restricción 
de los derechos- - Sin embargo, en el primero de los casos, la nacionalidad puede presentarse como un criterio de racionalización del ejercicio del sufragio, vinculado al orden público. En este supuesto, la cuestión se desplazaría hacia el examen de los límites de los derechos en relación con el orden público, cuestión que no me es posible abordar aquí.

\section{El papel de los derechos humanos en la gestión de la diversidad cultural}

Qué papel debe ser asignado a la cultura en la construcción de la idea de los derechos es una cuestión antigua. En la actualidad, para realizar esta asignación, debemos ser conscientes de que la globalidad ha producido dos grandes consecuencias en el ámbito cultural: por un lado, lo que podríamos denominar la «comunicación entre culturas», con lo que ello lleva de conocimiento de otras culturas o formas de entender el mundo y los seres humanos, de convivencia entre ellas y de tensión; por otro, lo que podríamos denominar la «creación de culturas», fruto precisamente de esa comunicación. En efecto, la globalidad ha producido también la fusión de prácticas culturales y, a partir de ella, la aparición de nuevos referentes normativos.

De esta forma, la globalización ha sido objeto de críticas tanto por aquellos que la consideran expresión de un intento de dominio de una cultura sobre otras, como por aquellos que la entienden como la causa principal de la pérdida de la identidad de los individuos, cuanto por aquellos que la acusan de promover la desaparición de las culturas cuantitativamente minoritarias o menos poderosas. En muchas de estas críticas, los derechos aparecen vinculados a la globalización, y forman parte de esa estructura de dominación e imposición de un modelo cultural.

La identidad cultural ha sido definida de maneras diversas. Lamo de Espinosa se ha referido a ella como: «[...] la ubicación propia y del otro en referencia a una cultura, la clasificación de un sujeto como perteneciente a un grupo que se supone tiene una específica cultura» ${ }^{7}$. Por su parte, la idea de cultura ha sido definida por este autor como:

[...] el conjunto de maneras de obrar, pensar o sentir específicas a un grupo humano. Se trata, pues, de repertorios de conducta, aparentemente reguladas por repertorios de normas relativamente unificadas e integradas, y sustentadas por un conjunto jerárquico de valores que supuestamente legitiman y hacen comprensibles y razonables esas normas de conducta y las prácticas que a ellas responden [...] en última instancia, una cultura no es sino un conjunto de prácticas legitimadas y, por supuesto, institucionalizadas ${ }^{8}$.

7 Lamo de Espinosa, E. «Fronteras culturales». En E. Lamo de Espinosa (editor). Culturas, estados, ciudadanos. Madrid: Alianza, 1995, p. 65.

8 Ibid. p. 15. 
Desde esta forma de entender la idea de cultura, esta posee una dimensión individual, de aceptación de su existencia y de su valor, y por tanto de subjetividad, que necesariamente se proyecta sobre la noción de identidad cultural. La existencia y el valor de una cultura como expresión de un conjunto de prácticas se producen siempre y cuando encontremos individuos que las asuman.

Por otro lado, si pretendemos objetivar la idea de cultura, finalmente llegaremos a una conclusión similar. Tylor entiende por cultura un «[...] todo complejo que incluye el conocimiento, las creencias, el arte, la moral, las leyes, las costumbres y cualesquiera otros hábitos y capacidades adquiridos por el hombre en cuanto miembro de una sociedad» ${ }^{9}$. Por su parte, Kymlicka se refiere a la «cultura societal», y afirma que se trata de la $«[\ldots]$ cultura que proporciona a sus miembros unas formas de vida significativas a través de todo el abanico de actividades humanas, incluyendo la vida social, educativa, religiosa, recreativa y económica, abarcando las esferas pública y privada» ${ }^{10}$.

Pues bien, esta forma de entender la cultura trae consigo dos consecuencias. Por un lado, la posibilidad de entender a las culturas como teorías políticas y morales; por otro, la de plantear la existencia de diferentes culturas -incluso, en un sentido extremo, sin duda algo exagerado, tantas como decidan los individuos- ${ }^{11}$.

Precisamente, la existencia de diferentes culturas es lo que identifica al llamado «pluralismo cultural» y, en cierto sentido, al multiculturalismo. El término multiculturalismo posee diferente significados. En ocasiones se asocia a los planteamientos multiculturalistas una serie de rasgos que necesariamente no tienen por qué compartirse y que hasta cierto punto se excluyen. Así, por ejemplo, se asocia multiculturalismo con relativismo, pero también con objetivismo y con antipluralismo. Se afirma que la defensa del multiculturalismo implica considerar que todas las culturas son igualmente valiosas, pero también se afirma que finalmente produce una jerarquización entre culturas y que, al justificar el fomento de determinadas prácticas culturales, se sitúa frente al pluralismo ${ }^{12}$. Pues bien, esos rasgos, aunque pueden estar presentes en algunas posiciones multiculturalistas, no son partes esenciales de ese término.

En un sentido genérico, es posible diferenciar dos grandes tipos de utilizaciones que podríamos identificar como «descriptivas» $\mathrm{y}$ «normativas». Desde un punto de vista descriptivo, se utiliza para aludir una situación de hecho, como puede ser la convivencia de diferentes culturas y prácticas sociales en un determinado territorio. Desde un punto de vista normativo, el término multiculturalismo se utiliza para exponer un juicio

9 Tylor, E.B. Cultura primitiva. Los orígenes de la cultura. Madrid: Ayuso, 1977, p. 19.

10 Kyмlicka, W., Ciudadanía multicultural. C. Castells (traductora). Barcelona: Paidós, 1996, p. 112.

11 Véase WALDRON, J. «Minority Cultures and the Cosmopolitan Alternative». University of Michigan Journal of Law, 25/3, 1992, p. 762

12 Véase SARTORI, G. La sociedad multiétnica. Pluralismo, multiculturalismo y extranjeros. Madrid: Taurus, 2001, pp. 79 y 80. 
valorativo — es decir, normalmente positivo — sobre esa situación de hecho. Dentro del planteamiento normativo es a su vez posible diferenciar entre multiculturalismo en sentido estricto y el interculturalismo ${ }^{13}$. El modelo de la interculturalidad pretende superar el multiculturalismo al entender que este camino se limita a la aceptación de diferentes culturas y no a su potenciación ${ }^{14}$.

En todo caso, la objetivación de la cultura en el ámbito social, presente siempre que se habla de pluralismo o multiculturalismo, hace que las distintas posiciones culturales desempeñen un papel similar al de una teoría de la justicia, al de una teoría ética o al de una teoría política, al igual que lo hacen las teorías de los derechos, e incluso posibilita hablar de una cultura de los derechos y situar un modelo de identidad cultural en ese ámbito - representada por la dignidad humana, entendida en clave de derechos- En efecto, la referencia a la existencia de diferentes prácticas culturales supone, entre otras cosas, admitir que existen repertorios normativos diferentes, formas de entender el mundo y las relaciones sociales que difieren entre sí, y que aparecen como expresión de tradiciones asumidas por individuos y colectivos. En la medida en que dichos repertorios poseen una dimensión normativa, cuentan con los rasgos que tienen las diferentes propuestas éticas y políticas presentes en los debates que se desenvuelven en esos ámbitos. La especificidad de estos repertorios radica en la manera en la que se justifican — normalmente, la tradición-.

El profesor Pérez Luño ha afirmado que «[...] el pluralismo cultural, o sea, el reconocimiento de una realidad plural de tradiciones e instituciones políticas y culturales, no debe confundirse con el relativismo cultural, es decir, con el mito de que todas las formas culturales poseen idéntico valor» ${ }^{15}$. Y, en este sentido, la valoración de toda cultura —al igual que la valoración de cualquier teoría ética o política - será consecuencia del juicio que nos merezcan sus prácticas respecto de los seres humanos, juicio que será tomado desde una serie de referentes y que deberá tener en cuenta que la existencia de esa cultura es consecuencia de la aceptación, por un conjunto de seres humanos, de las prácticas que la definen.

Una teoría de los derechos puede ser utilizada como referente de esa valoración y desde sus presupuestos, consciente de la importancia de la

13 ComohaseñaladoSolanes, «[...]elmulticulturalismoimplicaelrespetoalasdiversasculturasylaorganización socialdeformaqueexistanlasmismasposibilidadesparaparticiparporpartedesusmiembrosintegrantes[...] Setratadeadoptar un puntodepartidaenelque 'elotro'es aceptadocomointerlocutorválidoy, a partir deeste momento, puedehablarsedeunanuevaculturamezcladelasexistentes».Porsuparte,lainterculturalidad «[...] supondría una respuesta normativa frente a esa realidad existente». SoLANES, A. «Una respuesta al rechazo racista de la inmigración: la interculturalidad». Anuario de Filosofía del Derecho, tomo XV, 1998, pp. 131 y 133.

14 Coneste planteamiento, se tratadeabandonar dos ideas. En primer lugar, la idea de que la diversidad cultural es un valornegativo o positivo más, ynoun hechosocial. En segundolugar, la consideración comouniversal deundeterminadomodelocultural-quesecorrespondenormalmenteconeloccidental-.VéaseDeLuCAS,J. “¿Elogio de Babel? Sobre las dificultades del Derecho frente al proyecto intercultural». Anales de la Cátedra Francisco Suárez, № 31, 1994, pp. 21 y siguientes.

15 Pérez LuÑo, A.E. «La universalidad de los derechos humanos». En J.A. López García y J.A. Del Real, LoS derechos: entre la ética, el poder y el Derecho. Madrid: Dykinson, 2000, p. 62. 
independencia y la autonomía, debe abrirse a otros modelos e integrar dimensiones de otras teorías y culturas. De esta forma, la atención a la dimensión cultural es una exigencia de toda teoría de los derechos que parta de la defensa de la idea de sujeto moral y que quiera ser coherente con ella.

La teoría de los derechos debe optar frente al multiculturalismo por mantener una posición normativa: una postura que implique el respeto a las diferentes culturas, a las diferentes teorías de la justicia y, en definitiva, a la igual autonomía de todo ser humano (el respeto al «otro»). En este sentido, no tiene por qué descartar desde el principio la posibilidad de rechazar prácticas, teorías o culturas enfrentadas a los rasgos básicos de la teoría de los derechos, ni la posibilidad de justificar medidas de diferenciación positiva hacia sujetos y colectivos, derivadas de su consideración como sujetos morales - y no tanto de su pertenencia a una nación o a una cultura-.

La argumentación culturalista es relevante para la teoría de los derechos, si bien en un segundo plano. La teoría de los derechos debe discutir sobre razones y argumentos; más allá de estos —donde la dimensión cultural tiene cabida pero en esa forma-, la cuestión cultural será un añadido cuantitativo relevante pero, como ya he señalado, tan solo en segundo plano.

En efecto, la teoría de los derechos no puede manejar una idea monolítica de estos, sino que debe estar abierta, en el mayor grado posible, a diferentes teorías y puntos de vista, y atender tanto a su sentido como a su justificación. Ahora bien, este carácter abierto de los derechos es consecuencia de la discusión racional sobre el significado de las diferentes teorías, con lo que en esa discusión el argumento de la tradición, o cualquier otro que trate de justificar una práctica apelando única y exclusivamente a la cultura, no parece tener cabida, al menos en un primer momento - esto es, en el momento en el que discutimos sobre la «bondad» de la práctica-. Esto no significa que la dimensión social carezca de relevancia en el ámbito de la teoría de los derechos, sino más bien que toda proposición normativa debe justificarse desde razones.

Todo ello implica necesariamente manejar una teoría de los derechos de carácter mínimo. Una teoría dinámica, abierta y, en cierta manera, contextualizada. Una teoría de los derechos abierta a dimensiones culturales, o si se quiere, una cultura de los derechos abierta a otras culturas. Y ello se logra al integrar la idea de disenso en el discurso de los derechos, con lo que, en términos genéricos, el respeto a la diferencia cultural no es sino la conclusión lógica del respeto a la diferencia como parte integrante de la manera correcta de entender los derechos. 